ISLAMIC BANKING: Jurnal Pemikiran dan Pengembangan Perbankan Syariah, Volume 7 Nomor 2 Edisi Februari 2022

\title{
DAMPAK PELAKSANAAN MERDEKA BELAJAR KAMPUS MERDEKA DI UNIVERSITAS TRILOGI (STUDI KASUS: PRODI MANAJEMEN)
}

\author{
Fanny Suzuda Pohan \\ Program Studi Manajemen, Fakultas Ekonomi Bisnis dan Humaniora, Universitas Trilogi \\ Email: fannysuzudapohan@trilogi.ac.id \\ Zainul Kisman \\ Program Studi Manajemen, Fakultas Ekonomi Bisnis dan Humaniora, Universitas Trilogi \\ Email: zainulkisman@trilogi.ac.id
}

\begin{abstract}
This study aims to see the impact of the implementation of Merdeka Learning Merdeka Campus at Trilogy University, especially Management Study Program. This study uses primary data and secondary data. The population in this study were students of the Trilogy University Management Study Program as many as 685 students. The sample used was 312 students. The analytical method used is descriptive method. Based on the survey given, $78.53 \%$ of students believe that MBKM activities have an impact on their additional competencies, $73.08 \%$ of students believe that MBKM activities are extended in terms of solving problems and $73.4 \%$ of students think that MBKM activities for higher education are in accordance with the needs of future graduates. future.
\end{abstract}

Keywords: MBKM; Descriptive Method; Management

\begin{abstract}
Abstrak
Penelitian ini bertujuan melihat dampak pelaksanaan Merdeka Belajar Kampus Merdeka di Universitas Trilogi khususnya Prodi Manajemen. Penelitian ini menggunakan data primer maupun data sekunder. Populasi dalam penelitian ini adalah mahasiswa Prodi Manajemen Universitas Trilogi sebanyak 685 mahasiswa. Sampel yang digunakan sebanyak 312 mahasiswa. Metode analisis yang digunakan adalah metode deskriptif. Berdasarkan hasil survey yang diberikan 78,53\% Mahasiswa yakin kegiatan MBKM memberikan dampak terhadap kompetensi tambahan mereka, 73,08\% mahasiswa yakin kegiatan MBKM memperluas prespektif dalam menyelesaikan masalah dan 73,4\% mahasiswa berpendapat kegiatan MBKM untuk perguruan tinggi sesuai dengan kebutuhan lulusan di masa mendatang.
\end{abstract}

Kata Kunci: MBKM; metode deskriptif; manajemen 


\section{Dasar Pemikiran}

Pada awal tahun 2020 Kementerian Pendidikan dan Kebudayaan memberlakukan kebijakan baru di bidang pendidikan tinggi melalui program Merdeka Belajar Kampus Merdeka (MBKM). Tujuan dari program ini adalah untuk meningkatkan keselarasan antara lulusan pendidikan tinggi dengan dunia usaha dan industri serta masa depan yang semakin cepat mengalami perubahan.

Sebagai sebuah perguruan tinggi yang mempunyai komitmen tinggi dalam pengembangan kualitas pendidikan, maka Universitas Trilogi menyambut baik kebijakan MBKM dan telah mengimplementasi dalam bentuk kegiatan pembelajaran sesuai dengan ketentuan yang berlaku dalam Permendikbud No. 3 Tahun 2020 Tentang Standar Nasional Pendidikan Tinggi (SNPT). Pada semester gasal 2020 mahasiswa Universitas Trilogi yang diterima dalam kegiatan pembelajaran MBKM Dikti sebanyak 27 mahasiswa terdiri dari 2 pertukaran mahasiswa (1 internasional dan 1 nasional), 13 mahasiswa magang, dan 12 mahasiswa studi independen. Dari Prodi Manajemen sendiri diterima 3 mahasiswa untuk kegiatan magang dan 1 mahasiswa untuk kegiatan studi Independen.

Sebelum memasuki semester ke 2 dari kegiatan pembelajaran MBKM ini dirasakan perlu dilakukan analisis dampak pelaksanaan Merdeka Belajar Kampus Merdeka di Universitas Trilogi khususnya pada Prodi Manajemen. Dari latar belakang ini, tujuan dari penelitian ini adalah untuk melihat dampak pelaksanaan Merdeka Belajar Kampus Merdeka di Universitas Trilogi pada Prodi Manajemen.

\section{Metode Penelitian}

Penelitian ini dilakukan pada bulan Desember 2021 di Prodi Manajemen Universitas Trilogi, Jakarta. Penelitian ini menggunakan data primer yang bersumber dari hasil survey dan wawancara. Metode pengumpulan data berdasarkan sumber data sumber data primer yakni responden mahasiswa langsung mengisi kuesioner yang dikirim ke masing-masing mahasiswa Prodi Manajemen. Pengumpulan data ini untuk mendapatkan data variabel tanggapan mahasiswa tentang kegiatan MBKM. Sehingga dapat ditetapkan kegiatan intervensi terhadap kegiatan MBKM ini; sumber data skunder yakni melalui LPPM, Prodi Manajemen dan studi pustaka dari hasil-hasil penelitian 
ISLAMIC BANKING: Jurnal Pemikiran dan Pengembangan Perbankan Syariah, Volume 7 Nomor 2 Edisi Februari 2022

terdahulu maupun tulisan-tulisan lain yang berkaitan dengan tujuan survei ini. Sumbersumber ini untuk melengkapi dan mengkonfirmasi data primer; dan populasinya adalah seluruh mahasiswa Program Studi Manajemen Universitas Trilogi yang terdaftar aktif sebanyak 685 mahasiswa. Dan yang mengembalikan kuesioner sebanyak 312 mahasiswa. Kegiatan dalam analisis data dilakukan dengan mengkelompokkan data berdasarkan variabel masalah. Membuat tabulasi data berdasarkan variabel. Kemudian melakukan perhitungan dan analisa secara deskriptif. Menggunakan hasil kuesioner serta hasil-hasil penelitian terdahulu disusun rekomendasi untuk memecahkan masalah dan mengantisipasi masalah.

\section{Pembahasan}

Pada bagian ini akan menjelaskan deskripsi data yang berhasil dikumpulkan dari responden. Berdasarkan data ini akan dilihat profil data penelitian dan hubungan antar variabel dalam penelitian. Responden dalam penelitian ini adalah mahasiswa Universitas Trilogi sebanyak 312 mahasiswa yang mengembalikan kuesioner dari keseluruhan jumlah mahasiswa prodi manajemen sebanyak 685 mahasiswa.

\section{Pengetahuan Mahasiswa Prodi Manajemen tentang MBKM}

Tabel 1.

Persentase jumlah mahasiswa mengetahui tentang kebijakan Merdeka Belajar-Kampus Merdeka (MBKM)

\begin{tabular}{|l|r|}
\hline \multicolumn{1}{|c|}{ Keterangan } & \multicolumn{1}{c|}{$\%$} \\
\hline Belum mengetahui sama sekali. & 15.45 \\
\hline Mengetahui sedikit & 5.69 \\
\hline Mengetahui sebagian besar isi kebijakannya & 28.18 \\
\hline Mengetahui kebijakan secara keseluruhan & 50.68 \\
\hline
\end{tabular}

Berdasarkan Tabel 1 diatas, meskipun banyak mahasiswa prodi Manajemen yang telah mengetahui baik sebagian maupun keseluruhan yakni 78,86\% tentang kebijkan MBKM. Namun masih ada 15,45\% mahasiswa yang belum mengetahui sama sekali tentang kebijakan MBKM dan 5,69\% yang hanya mengetahui sedikit. Kedepan perlu usaha-usaha oleh Prodi maupun semua pihak agar persentase dapat terus diminimalkan. 
310 Fanny Suzuda Pohan \& Zainul Kisman, DAMPAK PELAKSANAAN MERDEKA BELAJAR KAMPUS

Menurut responden untuk meningkatkan pemahaman kebijakan MBKM maka media informasi yang bisa digunakan secara peringkat adalah:

1. Kanal daring Kemendikbud.

2. Kegiatan sosialisasi luring/daring yang diselenggarakan oleh Perguruan Tinggi.

3. Kanal komunikasi komunitas ( alumni atau dosen)

Sedangkan tingginya pemahaman mahasiswa tentang kebijakan MBKM saat ini karena program studi ini telah mempunyai program terdahulu yang sesuai dengan bentuk kegiatan MBKM. Hal tersebut dapat dilihat pada tabel 2 dibawah ini.

Tabel 2.

Program terdahulu yang sesuai dengan bentuk kegiatan MBKM

\begin{tabular}{|l|r|}
\hline \multicolumn{1}{|c|}{ Keterangan } & $\%$ \\
\hline $\begin{array}{l}|c| \\
\text { Sesuai (Misalnya : Praktek Magang Kerja; Pertukaran Pelajar;Kegiatan } \\
\text { Wira Usaha) }\end{array}$ & 68.27 \\
\hline Tidak Sesuai & 31.73 \\
\hline
\end{tabular}

Dari data jawaban responden terlihat pada Tabel 3 dibawah ini, pilihan mahasiswa bentuk kegiatan pembelajaran di luar program studi yang paling diminati adalah Magang/Praktik Kerja kemudian pertukaran pelajar dan kegiatan Wirausaha..

Tabel 3.

Bentuk kegiatan pembelajaran di luar program studi yang paling diminati

\begin{tabular}{|l|r|}
\hline \multicolumn{1}{|c|}{ Keterangan } & $\%$ \\
\hline Asistensi Mengajar di Satuan Pendidikan & 1.60 \\
\hline Kegiatan Wirausaha & 12.82 \\
\hline Magang/Praktik Kerja & 52.56 \\
\hline $\begin{array}{l}\text { Membangun Desa atau Kuliah Kerja Nyata Tematik } \\
\text { (KKNT) }\end{array}$ & 9.29 \\
\hline Penelitian/Riset & 0.96 \\
\hline Pertukaran Pelajar & 15.71 \\
\hline Proyek Kemanusiaan & 5.13 \\
\hline Studi/Proyek Independen & 1.92 \\
\hline
\end{tabular}


Berdasarkan Tabel 3 diatas maka untuk meningkatkan pemahaman mahasiswa tentang MBKM dan partisipasinya maka disarankan untuk mempertahankan bentuk kegiatan pembelajaran di luar program studi yang sudah ada dan diminati, seperti telah dijelaskan di atas.

\section{Dampak-Dampak Pelaksanaan Kegiatan MBKM}

Berdasarkan Tabel 1, 2 dan 3 diatas, meskipun ada kekurangan-kekurangan. Sebenarnya mahasiswa mendukung dilaksanakan kegiatan MBKM. Tabel 4 dibawah ini adalah dampak-dampak positif menurut perspektif mahasiswa yang mendorong pentingnya dilaksanakan kegiatan MBKM.

Tabel 4. Dampak-dampak pelaksanaan kegiatan MBKM

\begin{tabular}{|l|c|}
\hline Keterangan & $\%$ \\
\hline $\begin{array}{l}\text { Mahasiswa yakin kegiatan MBKM memberikan kompetensi } \\
\text { tambahan }\end{array}$ & 78,53 \\
\hline $\begin{array}{l}\text { Mahasiswa yakin kegiatan MBKM memperluas prespektif dalam } \\
\text { menyelesaikan masalah. }\end{array}$ & 73,8 \\
\hline $\begin{array}{l}\text { Mahasiswa berpendapat kegiatan MBKM untuk perguruan tinggi } \\
\text { sesuai dengan kebutuhan lulusan di masa mendatang }\end{array}$ & 73,40 \\
\hline Ketertarikan mahasiswa terhadap program MBKM & 65,38 \\
\hline $\begin{array}{l}\text { Mahasiswa yakin kegiatan MBKM berimplikasi kuliah tetap tepat } \\
\text { waktu }\end{array}$ & 62,18 \\
\hline Mahasiswa sudah menyiapkan diri & 51.92 \\
\hline $\begin{array}{l}\text { Mahasiswa yakin kegiatan MBKM mampu membekali } \\
\text { kompentensi/keterampilan sebagai bekal bekerja setelah lulus. }\end{array}$ & 59,29 \\
\hline $\begin{array}{l}\text { Mahasiswa yakin peningkatan soft-skill setelah mengikuti } \\
\text { kegiatan MBKM }\end{array}$ & 45,51 \\
\hline $\begin{array}{l}\text { Mahasiswa menganggap penting MBKM untuk menghadapi } \\
\text { pasca kampus. }\end{array}$ & 42,31 \\
\hline
\end{tabular}

\section{Kekhawatiran ketika melakukan kegiatan MBКМ}

Kegiatan MBKM meskipun memberikan dampak positif namun harus mendapat perhatian dari Prodi Manajemen karena ada perasaan kekhawatiran dari sebagian mahasiswa tentang kegiatan MBKM ini. 
312 Fanny Suzuda Pohan \& Zainul Kisman, DAMPAK PELAKSANAAN MERDEKA BELAJAR KAMPUS

Tabel 5. Kekhawatiran Mahasiswa tentang Kegiatan MBKM

\begin{tabular}{|l|c|}
\hline Keterangan & \% \\
\hline Mengeluarkan biaya & 54,81 \\
\hline Kurangnya informasi & 27,56 \\
\hline Kurang ada dukungan dari kampus & 8,97 \\
\hline
\end{tabular}

Berdasarkan Tabel 5 diatas, menurut pendapat mahasiswa masalah pelaksanaan kegiatan MBKM dikhawatirkan akan menambah pengeluaran biaya bagi mahasiswa. Hal tersebut dapat dipahami karena kurangnya informasi yang diterima mahasiswa tentang MBKM (tabel 5 dan tabel 1) serta mahasiswa menganggap kurangnya dukungan dari kampus. Untuk mengatasi ini maka perlu sosialisasi yang lebih intensif tentang kegiatan MBKM serta usaha-usaha lain agar pelaksanaan MBKM optimal.

\section{Persiapan Pelaksanaan MBKM Agar Optimal}

Tabel 6. Persiapan Pelaksanaan MBKM

\begin{tabular}{|l|c|}
\hline \multicolumn{1}{|c|}{ Keterangan } & $\%$ \\
\hline $\begin{array}{l}\text { Mempelajari panduan MBKM dan kurikulum yang memfasilitasi } \\
\text { MBKM }\end{array}$ & 58.33 \\
\hline $\begin{array}{l}\text { Mengikuti seleksi kegiatan dan menyiapkan syarat-syarat yang } \\
\text { dibutuhkan }\end{array}$ & 18.59 \\
\hline Proaktif dalam mempersiapkan kegiatan pembelajaran yang sesuai & 23.08 \\
\hline
\end{tabular}

Seandainya pelaksanaan MBKM ingin dilaksanakan secara serius dengan hasil yang optimal serta memberikan dampak-dampak yang positif maka menurut catatan survey ini perlu dipersiapkan buku panduan MBKM yang lebih komunikatif, prodi proaktif mempersiapkan kegiatan pembelajaran yang sesuai dengan kebutuhan industri pada saat ini maupun yang akan datang.

\section{Rekomendasi Mahasiswa.}

Tabel 7. Rekomendasi Mahasiswa

\begin{tabular}{|l|r|}
\hline \multicolumn{1}{|c|}{ Keterangan } & \multicolumn{2}{|c|}{$\%$} \\
\hline Tidak Tertarik & 0.32 \\
\hline Biasa saja & 40.06 \\
\hline Sangat Tertarik & 59.62 \\
\hline
\end{tabular}

Menurut tabel 7 diatas, hasil survey ini menunjukkan bahwa mahasiswa memberi saran bahwa kegiatan MBKM sebaiknya dilaksanakan karena 59,62\% mahasiswa prodi 
ISLAMIC BANKING: Jurnal Pemikiran dan Pengembangan Perbankan Syariah, Volume 7 Nomor 2 Edisi Februari 2022

manajemen sangat tertarik. Hasil ini sejalan dengan dampak-dampak positif (tabel 4) yang akan didapat mahasiswa apabila kegiatan ini jadi dilaksanakan.

\section{Simpulan}

Berdasarkan uraian-uraian diatas maka dapat disimpulkan kegiatan MBKM pada prodi manajemen akan berdampa pada pemberikan kompetensi tambahan, memperluas prespektif dalam menyelesaikan masalah, sesuai dengan kebutuhan lulusan di masa mendatang, kuliah tetap dapat tepat waktu dan meningkatan soft-skill. Berdasarkan kesimpulan diatas maka disarankan kegiatan MBKM ini sebaiknya dilaksanakan melalui tindakan praktis seperti kegiatan MBKM ini sesuai dengan kebutuhan dunia praktis/bisnis saat ini dan pengembangan teoris melalui kegiatan MBKM ini sejalan dengan perkembangan teoritis yang semakin multi dimensi.

\section{DAFTAR PUSTAKA}

Aji, R. S., \& Putra, M. I. (2021). Role Model Implementasi Kurikulum Merdeka Belajar Kampus Merdeka pada Program Studi Non-Agama. Working Paper.

Fatmawati, E. (2020). Dukungan Perpustakaan dalam Implementasi "Kampus Merdeka dan Merdeka Belajar". Jurnal Pustaka Ilmiah, 6(2), 1076-1087.

Fuadi, T. M., \& Aswita, D. (2021). Merdeka Belajar Kampus Merdeka (MBKM): Bagaimana Penerapan dan Kedala yang Dihadapi oleh Perguruan Tinggi Swasta di Aceh. Jurnal Dedikasi Pendidikan, 5(2), 603-614.

Kusumaningtyas, M. T., \& Rusydi, M. K. (2013). Pengaruh Persepsi dan Motivasi terhadap Minat Mahasiswa Jurusan Akuntasi Fakultas Ekonomi dan Bisnis Universitas Brawijaya Berkarir di Bidang Perpajakan. Jurnal Ilmiah Mahasiswa FEB Universitas Brawijaya.

Prihatini, P. A., \& Rachmawati, N. A. (2020). Pengaruh Motivasi, Efektivitas Pembelajaran Mata Kuliah Perpajakan dan Kesempatan Kerja di Bidang Perpajakan terhadap Minat Mahasiswa Akuntansi dalam Berkarir di Bidang Perpajakan. 2nd National Conference on Accounting and Auditing. Jakarta: Universitas Trilogi.

Peraturan Menteri Pendidikan dan Kebudayaan Republik Indonesia Nomor 7 Tahun 2020 Tentang Pendirian, Perubahan, Pembubaran Perguruan Tinggi Negeri, dan Pendirian, Perubahan, Pencabutan Izin Perguruan Tinggi Swasta. 
314 Fanny Suzuda Pohan \& Zainul Kisman, DAMPAK PELAKSANAAN MERDEKA BELAJAR KAMPUS ......

Prahani, et al. 2020. The Concept of "Kampus Merdeka" in Accordance with Freire's Critical Pedagogy. Studies in Philosophy of Science and Education (SiPoSE). https://www.researchgate.net/publication/341089491.

Stauffer, B. 2020. What Are 21 $1^{\text {st }}$ Century Skills?.Applied Educational System. https://www.aeseducation.com/blog/what-are-2 $1^{\text {st }}$-century-skills.

Wright, G.B. 2011. Student-Centered Learning in Higher Education. International Journal of Teaching and Learning in Higher Education. https://files.eric.ed.gov/fulltext/EJ938583.pdf. 